Revista Iberoamericana. Vol. LXIII, Núm. 180, Julio-Setiembre 1997; 509-523

\title{
CONTRIBUCIÓN A LA BIBLIOGRAFÍA DE JAVIER HERAUD
}

POR

\author{
Olga EsPejo
}

Javier Heraud nace en Miraflores en 1942 y muere trágicamente a la edad de 21 años, en 1963, en el río Madre de Dios frente a la ciudad de Puerto Maldonado, Perú.

Mucho se ha escrito sobre su muerte y las circunstancias que llevaron al fatal desenlace de esta joven vida, pero en esta oportunidad deseamos concentrarnos en la obra de Heraud como poeta. Representante importante de la Generación de los años 60 en el Perú y gran promesa para la poesía peruana.

Heraud se distingue como estudiante en el colegio Markham donde cursa sus etudios escolares. Recibe el Segundo Premio de su promoción y el Primer Premio de Literatura. Luego, a los 16 años ingresa a la Facultad de Letras de la Universidad Católica del Perú con el primer puesto de la clasificación general y en 1961, decide trasladarse a la Universidad Nacional Mayor de San Marcos (Lima, Perú).

El primer libro de Javier Heraud, El rio, se publica en 1960 y tiene muy buena acogida por la crítica. José Miguel Oviedo lo considera una obra espléndida y al poeta como la mejor esperanza de la poesía peruana entre las nuevas generaciones. Lo mismo sugiere Sebastián Salazar Bondy en "Dos libros, dos poetas" cuando señala: "Heraud se ha incorporado definitivamente a la poesía peruana como vanguardia de una 'nouvelle vague' que resume en sí, en su sabiduría e inspiración, la lenta elaboración de una lengua nueva que se inició con Eguren y Vallejo".

James Higgins en el capítulo séptimo de $A$ History of Peruvian Literature considera que:

The tone of his brief book, El rio, is one of youthful affirmation, expressing his confident acceptance of the adventure of life and his sense of integration with the world around him. The long title-poem, built around the metaphor of life as a river flowing towards the sea, places Heraud squarely in a Spanish poetic tradition that goes back as far as Manrique, but the traditional theme is renovated and enriched in an original and personnal manner. The simplicity of his expression, reminiscent of Machado, conveys a sense of freshness and immediacy and he displays a precocious mastery of his craft in a perfectly structured rhythmic architecture based on free verse, enjambment, reiteration and oppositions.

En 1960, Heraud comparte con César Calvo el Primer Premio en el concurso El Poeta Joven del Perú con El viaje, que luego publica en 1961. Sobre este poemario, Jorge Cornejo 
Polar en "Notas sobre la poesía de Heraud", considera: "[...] lo importante es la dimensión estética y el alcance simbólico del viaje [...] el viaje parece significar en varias ocasiones simplemente el sueño durante el cual se recorre comarcas y paisajes sin fin, pero en otros casos y más profundamente alude a una experiencia interior, quizás a una crisis radical acaecida al poeta en alguna ocasión".

James Higgins continúa su evaluación de la obra de Heraud señalando: “[...] motifs and simple metaphors are again to be found in El viaje, but here certainty gives way to anguished doubt and confusion as the maturing poet attains a deeper and more complex awareness of the realities of the world".

Por su poemario Estación reunida Heraud recibe postumamente el Primer Premio de Poesía en los Juegos Florales convocados por la Federación Universitaria de San Marcos (FUSM). El acta del premio concluye que: "Estación reunida posee singulares méritos que la hacen ampliamente merecedora de la distinción mencionada. Este jurado quiere señalar, en primer término, la profunda humanidad de sus temas y el decoro con que han sido tratados. Asimismo elogia la exquisita preocupación formal, que confiere a Estación reunida, a juicio de este jurado, una particular calidad en el conjunto de la poesía actual del Perú".

Gerardo Mario Goloboff en "Javier Heraud: la palabra en su límite" señala: "El poeta reelabora sus elementos permanentes; en el terreno de los significados: la tierra, la lluvia, el trigo, el sueño, la muerte; en el de la organización textual: las bisemias, los encabalgamientos movilizantes y visualizables, las oposiciones. Pero en su lenguaje se hace más hermético $[\ldots]^{\prime \prime}$.

Higgins concluye su evaluación sobre Heraud señalando que en Estación reunida el poeta: "[...] repudiates the world he had previously inhabited and believed in and he repudiates, too, a poetry based on solitary contemplation of self and nature in favour of a poetry with a collective focus".

En 1961 Heraud viaja a Moscú invitado por el Forum Mundial de la Juventud. Tiene oportunidad de conocer Rusia y luego viaja a Paris y Madrid. Durante su visita a la Ciudad Luz, Mario Vargas Llosa lo entrevista para un programa cultural que trasmitía a América Latina la Radiodiffusion-Television Française. Vargas Llosa le pregunta cómo situaría su poesía dentro de las tendencias poéticas peruanas y en su respuesta Heraud menciona: "Yo me preocupo actualmente, por hacer una poesía narrativa, una poesía descriptiva, clara, que se enriquezca con muchas cosas, con la música, con el cine, pero que no deje de ser poesía clara, poesía que pueda ser leída por todos". Y acerca de los poetas que más habían influenciado en su obra, observa: "Debo anotar ante todo poetas como Vallejo, como Neruda, entre los españoles preferentemente Antonio Machado, García Lorca y Miguel Hernández. En la poesía inglesa mucho admiro a Dylan Thomas".

En 1962 Heraud viaja a Cuba con una beca para estudiar cinematografía. En La Habana se enlista en el Ejército de Liberación Nacional del Perú bajo el seudónimo de Rodrigo Machado y compone varios poemas bajo este nombre. Ya en 1959 había usado este seudónimo escogido por su admiración a Rodrigo Díaz de Vivar, el Cid Campeador, y al poeta español Antonio Machado.

A más de treinta años de su muerte Javier Heraud es recordado por su importante aporte a las letras peruanas y por su sacrificio y amor a su patria y a su gente. Se le han rendido 
muchos homenajes y distinciones. Un aula de la Cooperativa Paramonga tomó el nombre de Javier Heraud, asimismo, en Piura una Cooperativa Agraria de Producción lleva también su nombre. Se han designado calles y promociones escolares con su nombre y Chabuca Granda, la inolvidable compositora peruana, le dedicó: "Las flores buenas de Javier".

\section{Obras de Heraud}

El río. Lima: Cuadernos de Hontanar, 1960.

El viaje. Lima: Ediciones Cuadernos Trimestrales de Poesía, 1961.

Poesias completas y homenaje. Lima: La Rama Florida, 1964.

Ensayo a dos voces, con César Calvo. Lima: Ediciones Cuyac, 1967.

Poemas. La Habana: Casa de las Américas, 1967.

Palabra de guerrillero: pequeña antología y homenaje. Selección y notas, Jesús Cabel. [Lima]: EWAGSA, [1970].

El río. Lima: Instituto Nacional de Cultura, 1972.

Poesías completas. 2a. ed. corr.y aum. Lima: Campodónico, 1973.

Poesías completas. 3a. ed. Lima: Campodónico, 1975.

Poemas. 2a. ed. La Habana: Casa de las Américas, 1975.

Poesías completas y cartas. Lima: Peisa, 1976.

Poesías completas. 4a. ed. Lima: F. Campodónico F., 1986.

Poesía completa. Prólogo de Javier Sologuren. Lima: Peisa, 1989.

\section{TRADUCCIONES}

Le fleuve suivi du Voyage (Ed. bilingüe traducida por Fanchita González Batlle). Paris: F. Maspero, 1971.

Season of Disenchantment: Selected Poems of Javier Heraud (Traducción de Pilar Zalamea, introducción de James Wright). [Los Angeles]: Illuminati, [1979].

Der Fluss/Die Reise/Zusammenkunft de Jahreszeiten $=$ El rio/El viaje/Estación reunida (Ed. bilingüe traducida por Eduardo Orrego Acuña). Lima: F. Campodónico F., 1994.

\section{Grabaciones}

Norma Alvizuri canta a Javier Heraud. Lectura de Jorge Chiarella Krüger. vol. 1. Lima: C. Otero Pollitt y C. Heraud, 1984 (Contiene: "Arte poética", "Lo difícil que es esperar el otoño", "Poemas a la tierra", "Mi casa", "Estación del desencanto", "Mi casa muerta", "Solo", "Hambre", "El río", "El canto de los ríos", "Yo no me río de la muerte", "Yo no soy el poeta que ustedes nombraron", "Epílogo", "Mi casa muerta" y testimonio en la voz de Javier Heraud.

\section{Poemas y cartas de Heraud en Antologías y Revistas}

Ahern, Maureen y David Tipton, eds. Peru: the New Poetry. London: Magazine Editions, 1970. 81-88. Incluye: "A guerrilla's word", "A guerrilla's goodbye", "Summer", “A 
new journey" y selecciones de "Earth poems". Traducción de Maureen Ahern. "Amor filial hecho poema: las cartas de Heraud". Vistazo 4.34 (1974): 20-21. Incluye tres cartas a su madre fechadas en La Habana el 13 y 22 de mayo y el 25 de diciembre de 1962. También un poema manuscrito: "Poema".

Baciu, Stefan, selección, prefacio, introducción y notas. Antología de la poesía latinoamericana, 1950-1970. 2 vols. Albany: State University of New York Press, 1974. vol. 2.(1022-1028). Incluye: "Elegía", "Palabra de guerrillero", "Arte poética", y "Lo difícil que es esperar el otoño sin moverse entre las higueras y la hoguera".

Boccanera, Jorge, ed. La novísima poesía latinoamericana. 2a. ed. México, D.F.: Editores Mexicanos Unidos, 1980. 227-229. Incluye: "Lo difícil que es esperar el otoño sin moverse entre las higueras y la hoguera" y "Arte poética".

Cáceres Urrutia, José, prólogo y notas. Antología de la poesía peruana. Lima: Ediciones Centauro, 1986. 70-71. Incluye: "Yo no me río de la muerte".

Donoso, José y William A. Henkin, eds. The TriQuarlerly Anthology of Contemporary Latin American Literature. 1. ed. New York: E.P. Dutton, 1969. 77-86. Incluye: "The Poem", "At Home", "Only", "Some Things", "The River" y "Epilogue". Traducción de Paul Blackburn.

Dorn, Edward y Gordon Brotherston, trad. Our World: Guerrilla Poems from Latin America = Palabra de guerrillero poesía guerrillera de Latinoamérica. 1a. ed. London: New York: Grossman Publishers in association with Cape Goliard, 1968. 14-25. Incluye: "Palabra de guerrillero", "Arte poética", "Las moscas", "Poema" y "El nuevo viaje". Poemas en español e inglés.

Durán, Cheli, ed. The Yellow Canary Whose Eye is so Black. New York: Macmillan, 1977. 318-325. Incluye: "Las moscas" y "Arte poética". Poemas en español e inglés. Traducción de Cheli Durán.

Escobar, Alberto, prólogo, selección y notas. Antología de la poesía peruana. Lima: Nuevo Mundo, 1965. 206-215. Breve apreciación de la obra de JH, bibliografía y los poemas: "El río", "Solo", "El deseo", "Recuento del año", "Verano" y "Destrucción de las sombras".

prólogo, selección y notas. Antología de lapoesía peruana. Lima, Perú: Peisa, 1973. Tomo 2 (58-68). Incluye introducción, breve bibliografía y los poemas: "El río", "Solo", "El deseo", "Recuento del año", "Verano" y "Destrucción de las sombras".

Fiction and Poetry from Spanish America, 1920-1970. New York: Viking, 1973. 428-431. Incluye: "Arte poética" y "Palabra de guerrillero". Poemas en español e inglés traducidos por Paul Blackburn.

Fierro, Enrique, selección. Antología de la poesía rebelde hispanoamericana. Montevideo: Ediciones de la Banda Oriental, 1967. 91. Incluye: "Palabra de guerrillero". "Four poems". TriQuarterly 15 (spring 1969): 241-244. Incluye: "The keys of death" (2 poemas), "A new journey" y "Summer". Traducción de Maureen Ahern Maurer.

González Vigil, Ricardo, prólogo, selección y notas. Poesia peruana: antología general, tomo 3, De Vallejo a nuestros días. Lima: Ediciones Edubanco, 1984. 252-258, 508509. Breve introducción, bibliografía y los poemas: "El río", "Yo no me río de la muerte", "El nuevo viaje" y "Las moscas".

Homo (Arequipa, Perú) 1.3 (1966): 12. Incluye: "Fragmento de Poema especial". 
Lagos, Ramiro, ed. Mester de rebeldía de la poesía hispanoamericana. Madrid: Ediciones dos Mundos, 1973. 396-397. Incluye: "Palabra de guerrillero".

Luby, Barry y Wayne H. Finke, eds. Anthology of Contemporary Latin American Literature, 1960-1984. Cranbury, N.J.: Associated University Presses, 1986. 178180. Incluye: "I do not laugh at death". Traducción de Wayne H. Finke.

Márquez, Robert, ed. Latin American Revolutionary Poetry = Poesía revolucionaria latinoamericana. New York: Monthly Review Press, 1974. 394-401. Incluye: "Alabanza de los días de destrucción y elogio de las sombras", "Palabra de guerrillero" y "Arte poética". Poemas en español e inglés.

Núñez, Estuardo, [ed.]. Poesía peruana, 1960: antología. Lima: Departamento de Literatura, Facultad de Letras, Universidad Nacional Mayor de San Marcos, 1961. 2732. Incluye: "El río".

Pellegrini, Aldo, ed. Antología de la poesía viva latinoamericana. 1a. ed. Barcelona: Seix Barral, 1966. 253-256. Incluye: "El río", "Yo no me río de la muerte" y "El poema".

Piélago (Lima) 1.3 (diciembre 1963): 18-21. Incluye tres poemas inéditos: "El nuevo viaje", "Estación del desencanto (fragmento)" y "Poesía de otoño".

"Poetas peruanos: Javier Heraud P.". Clasista 2 (mayo-junio 1963): 9. Incluye: "Las llaves de la muerte", "Poema", "Yo no me río de la muerte" y "El deseo".

Rodríguez Monegal, Emir, ed. The Borzoi Anthology of Latin American Literature. 2 vols. New York: A.A. Knopf, 1990. vol. 2 (858-861). Incluye: “The River" y "Epilogue". Traducción de Paul Blackburn.

Saldaña, Excilia, selección, prólogo y notas. Poesias de amor y combate. LaHabana: Gente Nueva, 1981. 249-252. Incluye: "Arte poética".

"Six poems by Javier Heraud". TriQuarterly 13-14 (fall/winter 1968/69): 106-115. Incluye: "The poem", "At home", "Only", "Some things", "The river" y "Epilogue". Traducción de Paul Blackburn.

Tamayo Vargas, Augusto, [ed.]. Nueva poesía peruana: antología. 1. ed. Barcelona: Ediciones Saturno, 1970. 99-106. Incluye: "El río (fragmento)", "Poema para Antonio Machado", “Arte poética", "El deseo", "Destrucción del verano e inicio del otoño entre sonrisas" y "Elegía".

Tipton, David, ed. Peru the New Poetry. New York: Red Dust, 1977. 109-115. Incluye: "A guerrilla's word", "A guerrilla's goodbye", "Summer", "A new journey" y selecciones de "Earth poems". Traducción de Maureen Ahern.

Toro Montalvo, César. [ed.]. Lima: AFA Editores, 1990. 747-751. Incluye: "El río". Unidad (Lima) 59 (4 de junio 1963): 8. Incluye: "Palabra de guerrillero".

\section{Crítica, Homenajes, Miscelánea}

Agurto, Gastón. “Javier Heraud, sueños que se truncan”. Caretas (Lima) 1262 (20 de mayo 1993): 44-45, 73. A los treinta años de la muerte de JH el autor conversa con tres jóvenes poetas: Antonio Stecher, Jaime Rodríguez y Paolo de Lima y recoge sus opiniones sobre el mismo. Incluye el poema inédito: "Balada de la vida de François Rabelais, autor del terrible monstruo Gargantúa y Pantagruel". 
"Amor filial hecho poema". Vistazo 34 (15 de mayo 1974): 20-21. Como homenaje de Vistazo a las madres en su día incluye tres cartas de $\mathrm{JH}$ a su madre.

Angeles Caballero, César A. "Intuición de la muerte en Javier Heraud: liminar" en Javier Heraud y las voces panegíricas. Huari, Ancash, Perú: [Imp. Huari], 1964. 9-16. Analiza partes de El viaje y El río y señala la muerte como imagen predominante en estos poemas.

"Pórtico" en Javier Heraud y las voces panegíricas. Huari, Ancash, Perú: [Imp. Huari], 1964. 5. Sirve de introducción al libro.

Baquerizo, Manuel. "La poesía peruana de 1960 " en Poesías completas y homenaje. Lima: La Rama Florida, 1964. 236-237. "Javier Heraud empieza su carrera poética exaltando las fuerzas de la vida, cantando diáfanamente la energía, la dichay la comunión de los hombres".

Barrantes Lingán, Alfonso. "Homenaje a Javier Heraud". F.U.S.M. (Lima) 1.3 (30 de mayo 1964): 4. Incluye partes del discurso de homenaje a JH en el primer aniversario de la muerte del poeta.

Béjar, Héctor. "[Carta]". Homo 1.3 (1966): 18. Carta dirigida a la revista y escrita desde la carceleta de la Prefectura de Lima el 13 de julio de 1966.

"Itinerario de Javier Heraud (I)". Correo (Lima) 15 de mayo 1975: 11. Recuerda su primer encuentro con JH en La Habana en 1962.

"Itinerario de Javier Heraud, Heraud (II)". Correo (Lima) 16 de mayo 1975: 11. Continúa contando acerca de los días pasados en La Habana con JH.

"Itinerario de Javier Heraud (final)". Correo (Lima) 17 de mayo 1975: 10. Recuerda los últimos días de JH y su caída en Puerto Maldonado.

Belli, Carlos Germán. "Palabras de Carlos G. Belli". Piélago (Lima) 1.3 (diciembre 1963): 26. Presentación a los estudiantes de la Universidad Mayor de San Marcos en homenaje a JH. También en: Javier Heraudy las voces panegíricas. Huari, Ancash, Perú: [Imp. Huari], 1964. 54-55.

Benavente, Félix. "A Javier Heraud" en Javier Heraud y las voces panegíricas. Huari, Ancash, Perú: [Imp. Huari], 1964. 35. Poema dedicado a JH.

Bendezú, Francisco. "Javier Heraud". Expreso (Lima) 15 de mayo 1980: 12. Escrito en el décimo séptimo aniversario de la muerte de JH: "La obra de Javier Heraud fue breve, estricta, fecunda y, ¡qué duda cabe!, premonitoria".

Cabel, Jesús. "El hombre-hombre" en Palabra de guerrillero: pequeña antología y homenaje. [Lima]: EWAGSA, [1970]. 67-69. Poema dedicado a JH.

"Javier Heraud" en Palabra de guerrillero: pequeña antología y homenaje. [Lima]: EWAGSA, [1970]. 1-2. "Javier Heraud siempre constituirá un noble ejemplo y valioso aporte para la literatura y la liberación de nuestros pueblos".

Calvo, César. "Elegía de sombra ante un cuerpo encendido" en Palabra de guerrillero: pequeña antología y homenaje. [Lima]: EWAGSA, [1970]. 63-66. Poema dedicado a JH. También en: Homo (Arequipa, Perú) 1.3 (1966): 3-5.

"Fragmento de un poema inédito". Piélago (Lima) 1.3 (diciembre 1963): 12-13. Poema dedicado a JH. También en: Javier Heraud y las voces panegíricas. Huari, Ancash, Perú: [Imp. Huari], 1964. 31-32. 
“Javier Heraud" en Poesias completas y homenaje. Lima: La Rama Florida, 1964. 219-220. Ataca la forma en que "La Prensa" se ha ocupado de publicar la noticia de la muerte de JH. También en: Unidad (Lima) 59 (4 de junio 1963): 8.

Campos, Mario. "Javier Heraud: el jóven que se fue". Expreso, (Estampa) (Lima) 18 de mayo 1975: 9. Recuerda a JH a los doce años de su muerte.

Castro Arenas, Mario. "Tres jóvenes poetas peruanos". La Prensa, Suplemento 7 días del Perú y del mundo (Lima) 30 de julio 1961: 23. Se ocupa de Arturo Corcuera, César Calvo y Javier Heraud. Considera que la poesía de JH es confidencial, mesurada y conceptual.

Castro Nue, Juan Carlos. "A 13 años de la muerte de Javier Heraud". Correo (Lima) 17 de mayo 1976: 7. Recuento biográfico como homenaje de aniversario.

Chávez Costa, Augusto. "Heraud, la muerte, las montañas y los pájaros". La Crónica (Lima) 3a. ed. (15 de mayo 1970): 2. "Javier Heraud escribió una vez: 'El cielo es nuestro. Nuestro el pan de cada día, hemos sembrado y cosechado el trigo y la tierra; son nuestros y para siempre nos pertenecen el mar, las montañas y los pájaros [...]' Su concepto de Patria era éste. Es el concepto del Poeta que expresa su amor sosegado envuelto en un hálito de paz. Entonces ¿para qué contaminarlo con la pasión política, la sangre y el odio del hermano [...]?".

Cisneros, Antonio. "Javier Heraud" en Palabra de guerrillero: pequeña antología y homenaje. [Lima]: EWAGSA, [1970]. 70-71. Poema dedicado a JH.

Corcuera, Arturo. “Añoranza de Javier" en Recuerdo y presencia de Javier Heraud. Lima: FUSM, 1963. "Conversaré de Javier como me vengan los recuerdos [...]". También en: Javier Heraud y las voces panegíricas. Huari, Ancash, Perú: [Imp. Huari], 1964. 56-58 y en: Poesias completas y homenaje. Lima: La Rama Florida, 1964. 216-218.

"Canción qué elegía". Expreso, (Estampa) (Lima) 18 de mayo 1975: 10. Poema dedicado a JH. También bajo "Canción antes que elegía" en: Palabra de guerrillero: pequeña antologia y homenaje. [Lima]: EWAGSA, [1970]. 72-74.

"Javier Heraud y su recuerdo de Moscú". Panorama internacional (Lima) 7 (julio 1972): 50. Cuenta las evocaciones de JH sobre su viaje por Europa, especialmente su visita a Moscú y Paris.

"Laurel para el héroe" en Poesías completas y homenaje. Lima: La Rama Florida, 1964. 213. "No vamos a llorarlo ahora que se ha ido: vamos a emularlo". También en: Unidad (Lima) 59 (4 de junio 1963): 8.

"El poeta" Piélago (Lima) 1.3 (diciembre 1963): 5. Poema dedicado a JH. También en: Recuerdo y presencia de Javier Heraud. Lima: FUSM, 1963. [6]; en: Javier Heraud y las voces panegíricas. Huari, Ancash, Perú: [Imp. Huari], 1964. 30; en: Poesías completas. 2a. ed. corr. y aum. Lima: Campodónico, 1973. 289; en: Poesías completas. 3a. ed. Lima: Campodónico, 1975. 289; y en: Poesías completas y cartas. Lima: Peisa, 1976. 196.

Cornejo Polar, Jorge. "Notas sobre la poesía de Heraud". Homo (Arequipa, Perú) 1.3 (1966): 13-17. Estudia los símbolos: otoño, río, viaje y el tema de la muerte en la poesía de JH. También en: Poesías completas. 2a. ed. corr. y aum. Lima: Campodónico, 1973. 338-353; en Poesías completas. 3a. ed. Lima: Campodónico, 1975. 338-353; y en: Poesias completas y cartas. Lima: Peisa, 1976. 212-225. 
Cristobal, Juan. “Canto a Javier Heraud”. Piélago (Lima) 1.3 (diciembre 1963): 9. Poema dedicado a JH. También en: Javier Heraudy las voces panegíricas. Huari, Ancash, Perú: [Imp. Huari], 1964. 36.

Delgado, Washington. "La poesía de Javier Heraud" en Imagen de la literatura peruana actual. Lima: Editorial Universitaria, 1968. Tomo 1 (77-88). Analiza la obra poética de JH y señala, entre otras cosas, su uso acertado del verso libre. También en: Poesías completas. 2a. ed. corr. y aum. Lima: Campodónico, 1973. 320-337; en Poesías completas. 3a. ed. Lima: Campodónico, 1975. 320-337; y en: Poesías completas y cartas. Lima: Peisa, 1976. 198-212.

"La muerte de Javier Heraud". Piélago (Lima) 1.3 (diciembre 1963): 14-16. "Meditemos [...] en el sentido de su breve existencia. Busquemos la raíz, la pulpa, el meollo de su tragedia. Entremos en la claridad de su muerte. No podremos rendirle homenaje mejor". También en: Unidad (Perú) 59 (4 dejunio 1963): 8; en: Javier Heraud y las voces panegíricas. Huari, Ancash, Perú: [Imp. Huari], 1964. 48-51; y en: Poesías completas y homenaje. Lima: La Rama Florida, 1964. 195-199.

"On the Death of Javier Heraud" en Peru, the New Poetry. Maureen Ahern y David Tipton, eds. London: Magazine Editions, 1970. 120-123. "Javier Heraud had the courage to choose his death, and the privilege of dying in a manner neither banal nor egotistical".

Escajadillo, Tomás G. "Javier y sus libros”. Expreso, (Estampa) (Lima) 18 de mayo 1975: 11. Recuerda la afición de $\mathrm{JH}$ a los libros y la repartición de éstos entre sus amigos en vísperas de su último viaje. También en: Recuerdo y presencia de Javier Heraud. Lima: FUSM, 1963. [14-17]; en Piélago (Lima) 1.3 (diciembre 1963): 24-26; en Javier Heraud y las voces panegíricas. Huari, Ancash, Perú: [Imp. Huari], 1964. 5962; y en Poesías completas y homenaje. Lima: La Rama Florida, 1964. 203-207.

Espinoza Seminario, Francisco. "Requiem" en Javier Heraud y las voces panegíricas. Huari, Ancash, Perú: [Imp. Huari], 1964. 40. Poema dedicado a JH.

Flores. Angel, ed. "Javier Heraud" en The Literature of Spanish America: a Critical Anthology. New York: Las Américas Pub. Co., 1966-67. vol. 4 (791-793). Breve introducción y bibliografía. "Heraud's poetry is miraculously fresh and simple".

Foster, David William. "Heraud, Javier" en Peruvian Literature: a Bibliography of Secondary Sources. Westport, Conn.: Greenwood Press, 1981. 154-156. Bibliografía. Frías, Ismael. "Javier no habría muerto ahora". La Crónica (Lima) 27 de mayo 1972: 3. Escrito como homenaje en el noveno aniversario de la muerte de $\mathrm{JH}$.

Gambetta, Fredy. "La casa de Javier". La Crónica, suplemento cultural (Lima) 19 de mayo 1982: 3. Cuenta sobre su visita a la casa de JH y entrevista con los padres del poeta. Goloboff, Gerardo Mario. "Javier Heraud: la palabra en su límite” en Poesías completas. 2a. ed. corr. y aum. Lima: Campodónico, 1973. 354-366. Analiza la obra poética de JH: "Su poesía es un permanente llamado a la muerte que le tocó asumir y una de las premoniciones más exactas sobre el doble carácter de fatalidad individual y de útil social que ese sacrificio contendría". También en: Poesías completas. 3a. ed. Lima: Campodónico, 1975. 354-366; y en: Poesías completas y cartas. Lima: Peisa, 1976. 225-235. 
Guillén, Nicolás. "[Carta]" en Poesías completas y homenaje. Lima: La Rama Florida, 1964. 224. Carta dirigida a Gustavo Valcárcel bajo el membrete de la Unión de Escritores y Artistas de Cuba. También en: Unidad (Lima) 61 (19 de julio 1963): 8. Gullón, Ricardo. "Heraud, Javier" en Diccionario de literaturaespañola e hispanoamericana. Madrid: Alianza Editorial, 1993. vol. 1 (697). Bio-bibliografía.

H.M. "Homenaje al poeta Heraud". Gente (Lima) 7.61 (8-30 junio 1964): 16. Considera Poesias completas y homenaje una "edición impecable y cuidadosamente editada".

Henderson, Carlos. "Javier Heraud, el que intenta" en Palabra de guerrillero: pequeña antología y homenaje. [Lima]: EWAGSA, [1970]. 75-77. Poema dedicado a JH.

Heraud Cricet, Jorge A. "En torno a los sucesos de Puerto Maldonado: la carta de un padre". Clasista 2 (mayo-junio 1963): 8. Sentida carta del padre de JH acerca de lo ocurrido en Puerto Mandonado. También bajo el título: "Documento histórico" en: Piélago (Lima) 1.3 (diciembre 1963): 3; bajo "Carta de Jorge A. Heraud" en: Javier Heraud y las voces panegíricas. Huari, Ancash, Perú: [Imp. Huari], 1964. 45-46; bajo "Carta del padre del poeta" en: Poesías completas y homenaje. Lima: La RamaFlorida, 1964. 13-14; en: Poesías completas. 2a. ed. corr. y aum. Lima: Campodónico, 1973. 1517; en: Poesías completas. 3a. ed. Lima: Campodónico, 1975. 15-17; y en Poesías completas. 4a. ed. Lima: Campodónico, 1986. 15-17.

Heraud Pérez, Cecilia. Vida y muerte de Javier Heraud: recuerdos, testimonios y documentos. F. Campodónico F., ed. 1a. ed. Lima: Mosca Azul, 1989. Concienzudo estudio biográfico escrito y compilado por la hermana de JH a los veinticinco años de la muerte del poeta.

Herrera de Angeles, Orfelinda. "Era sólo un poeta" en Javier Heraud y las voces panegíricas. Huari, Ancash, Perú: [Imp. Huari], 1964. 19-20. Poema dedicado a JH.

Hidalgo, Alberto. "Casi poema a Heraud". Piélago (Lima) 1.3 (diciembre 1963): 6-7. Poema dedicado a JH. También en: Javier Heraudy las voces panegiricas. Huari, Ancash, Perú: [Imp. Huari], 1964. 21-22. El mismo poema bajo el título: "Niño bandera" en Palabrade guerrillero: pequeña antologiay homenaje. [Lima]: EWAGSA, [1970]. 78-80.

Higgins, James. "The new poetry" en A History of Peruvian Literature. Liverpool: F. Cairns, 1987. 327, 328-330, 332. Analiza la obra de JH.

Hildebrandt, César. "Javier Heraud: nueve años después". Caretas (Lima) año 22, no. 457 (22 de mayo 1972): 42-44. Entrevista a Jorge Heraud Cricet, padre del poeta.

Hinojosa, Gonzalo. "Javier Heraud en el cine". La Prensa (Lima) 8 de marzo 1975: 9. Da razón sobre un documental sobre JH realizado por el Grupo de Cine Liberación sin Rodeos (Perú).

Holguín Núñez del Prado, Oscar. "[Carta]”. Oiga (Lima) 325 (23 de mayo 1969): 3. "Escribo a raíz del artículo de Winston Orrillo en el último número de Oiga sobre Javier Heraud, porque considero que nunca estará de más insistir sobre la vida, la obra y la personalidad de este poeta".

Jamis, Fayad. "Carta de Cuba". Piélago (Lima) 1.3 (diciembre 1963): 32. Carta a Arturo Corcuera: "Javier Heraud ha escrito con su muerte, a pesar de las balas explosivas que derramaron su sangre en lluvia de estrellas rojas, el más bello y poderoso de sus poemas". También en: Poesías completas y homenaje. Lima: La Rama Florida, 1964. 210. 
“Javier Heraud: vida y poesía". El Pueblo (Arequipa, Perú) 5 de junio 1969: 13. "El río, es en sustancia, la crónica gozosa del descubrimiento de la propia posibilidad vital y la del mundo que entrega sus dones que se adivina ya al final del poema como indignado por la muerte en este caso las 'aguas turbias' de los océanos".

“Javier y César". El Comercio, Suplemento Dominical (Lima) 2 de julio 1967: 30. Evalúa Ensayo a dos voces de JH y César Calvo: "Es no sólo un conmovedor testimonio de la amistad de dos poetas fraternos [...] sino, además, como anota Cisneros, 'un hermoso documento de amor a la poesía"".

"Juegos Florales Universitarios". F.U.S.M.(Lima) 1 (marzo 1964): 5. Cubre las festividades durante la semana del 20 al 30 de noviembre de 1963, organizadas por la Federación Universitaria de San Marcos (Lima, Perú) donde se llevaron a cabo actos culturales y se rindió homenaje a JH otorgándosele postumamente el Primer Premio por Estación reunida.

La Torre, Alfonso. "Homenaje a Javier Heraud". El Comercio gráfico (Lima) 24 de junio 1964: 6. Escrito en ocasión del primer aniversario de la muerte de JH y de la publicación de sus Poesias completas y homenaje. Señala las influencias de Eliot y Proust.

Lévano, César. "Marcha fúnebre a Javier Heraud" en Palabra de guerrillero: pequeña antologia y homenaje. [Lima]: EWAGSA, [1970]. 81-83. Poema dedicado a JH.

"Una primavera florida: libros de versos que no sólo interesan a la literatura". Caretas (Lima) 297 (setiembre 1964): 26-29. Artículo dedicado a Carlos Germán Belli y a JH. Sobre Heraud señala: "Rasgo que todos reconocen en Heraud es la maestría del lenguaje, el dominio de la forma [...]. Poesía sencilla y dramática, nacida no del calor de la improvisación sino de un "trabajo de alfarero"".

McMurray, George R. "Peru” en Spanish American Writing Since 1941: a Critical Survey. New York: Ungar, 1987. 190. Menciona brevemente a JH en el tercer capítulo dedicado a la poesía. "A confirmed idealist, he viewed poetry not only as a weapon of liberation from political oppression, but also as a means of redemption for all mankind".

Milla Batres, Carlos, ed. "Heraud, Javier" en Diccionario histórico y biográfico del Perú siglos $X V$ - $X X$. Lima: Editorial Milla Batres, 1986. Tomo IV, F-H(354-55). Biografía. ed. "Heraud, Javier" en Enciclopedia biográfica e histórica del Perú: siglos XIXXX. Lima: Editorial Milla Batres, 1994. Tomo 5, G-I (162-163). Bio-bibliografía.

Mora, Tulio. "Lo mataron y se acabó". Marka (Lima) 204 (14 de mayo 1981): 29. Cuenta sus entrevistas con el profesor de literatura y con estudiantes de quinto año de secundaria del colegio Markham donde estudió JH.

Muñoz M., Antonio. “Javier Heraud en el viaje de los años”. Nueva (Perú) 24 (mayo 1972): 24-25. Habla sobre la vida y obra del poeta.

Naranjo, Reynaldo. "Ensayo a dos voces: una generación". Expreso (Lima) 24 de julio 1967: 14. "El libro [...] recientemente publicado, mueve a pensar en un análisis de lo que se ha dado en llamar la 'Generación del 60"”.

"Javier Heraud". Unidad (Lima) 59 (4 de junio 1963): 8. 34. Poema dedicado a JH. También en: Javier Heraud y las voces panegíricas. Huari, Ancash, Perú: [Imp. Huari], 1964. 
Neruda, Pablo. "[Carta]". Piélago(Lima) 1.3 (diciembre 1963): 4. "Me doy cuenta de que una gran herida ha quedado abierta en el corazón del Perú y que la poesía y la sangre del joven caído siguen resplandecientes, inolvidables". También en: Poesías completas y homenaje. Lima: La Rama Florida, 1964. 225 y bajo "Mensaje de Pablo Neruda sobre Javier Heraud" en Javier Heraud y las voces panegíricas. Huari, Ancash, Perú: [Imp. Huari], 1964. 47.

Núñez, Estuardo. La literatura peruana en el siglo XX: 1900-1965. 1a. ed. México, D.F.: Editorial Pormaca, 1965. Examina la literatura de este período. JH es mencionado en páginas 50,57,58 y 232. "Poemas significantes y maduros, (El rio, El viaje), cristalinos y puros, nutridos de experiencias primarias, con los hombres y la vida, a veces melancólicos por su cercanía al dolor humano" (232).

O’Hara, Edgar. "Javier Heraud, el artesano". Marka (Lima) 204 (14 de mayo 1981): 2829. Analiza principalmente el lenguaje y temas en la poesía de JH: "Poesía de alfarero, cocida con inteligencia y sensibilidad".

"Temas y motivos de la poesía de Javier Heraud". Tesis de Bachillerato. Lima: Pontificia Universidad Católica, 1978. 193 p. Estudia las influencias, recursos estilísticos y temas en El rio, El viaje y Estación reunida.

"La totalidad en la poesía de Javier Heraud". Marka no. 181 (27 de noviembre 1980): 40-41. Escrito en conmemoración de los veinte años de la publicación de El río: "Las líneas que siguen intentan acercarse a una de las preocupaciones de la poesía de Heraud en sus tres libros [...] el tema es la búsqueda de un mundo pleno".

Ojeda, Juan. "Ardiente sombra (fragmento)". Piélago (Lima) 1.3 (diciembre 1963): 23. Poema dedicado a JH. También en: Javier Heraud y las voces panegíricas. Huari, Ancash, Perú: [Imp. Huari], 1964. 38-39.

Orrillo, Winston. "Heraud: hacia el X aniversario". Expreso (Lima) 12 de mayo 1973: 19. Menciona el bautizo de un pueblo joven de Chimbote con el nombre Javier Heraud y la dedicación del Primer Concurso Nacional de Poesía Escolar auspiciado por el diario Expreso de los Trabajadores del Perú también con el nombre Javier Heraud.

"Javier Heraud: el cuarto, los libros y la viva palabra del poeta". Oiga (Lima) 324 (16 de mayo 1969): 34-35. Recuerda al poeta: "Sí, partió y volvió ese 15 de mayo de 1963. Volvió con su poesía de alfarero, con sus nuevos cantos para el amor y la redención del hombre".

"Poesía peruana actual: dos generaciones". Cuadernos hispanoamericanos 228 (1968): 620-662. El autor evalúa varios poetas de los años 50 y 60: "La poesía de Heraud se distinguía por el canto a los temas sencillos, cotidianos - la casa, la familia, los amigos, el amor- desde los que proyectaba a los temas eternos del hombre". Incluye: "Arte poética" y "Fragmentos".

Ortega, Julio. "Biografía de los sesentas: la poesía en el Perú". Iberoromania (Tubingen, Germany) 34 (1991): 122-30. Considera a JH y a Luis Hernández dos de los poetas con más talento de esta generación. "Heraud es un héroe trágico, aquel que excede a su discurso no con su vida sino con su muerte, a la que perpetúa; funda, así, un comienzo que es un fin de los tiempos: un comienzo adelantado, que ocurre como el destiempo de la negatividad hecha fuerza creadora". 
"La muerte de Heraud". Expreso (Lima) 19 de junio 1967: 11. Escrito a los cuatro años de la muerte del poeta evalúa los motivos de JH de participar en la guerrilla, el compromiso del poeta y el significado de su muerte.

"La nueva poesía peruana". Correo (Lima) 2 de abril 1964: 4. Se ocupa de varios poetas. Sobre JH considera que: "Persiste en El viaje el tema de la muerte [... y] el tiempo es preocupación esencial de esta poesía [...] Javier Heraud ha dejado una poesía de verdadero mérito y pudo esperarse de él una producción cada vez más honda y depurada". También en: Poesias completas y homenaje. Lima: La Rama Florida, 1964. 241-242.

"Los poetas jóvenes". La tribuna (Lima) 20 de agosto 1961: 5. Se ocupa de Javier Heraud y César Calvo a raíz del recibimiento del Primer Premio en el concurso El Poeta Joven del Perú, que ambos poetas compartieron. Considera que El viaje es un libro de testimonio en el que el tiempo ocupa una idea central y concluye: "Hay atisbos en este libro del verdadero poeta que esperamos de él".

"Los poetas terribles del 60". La República, Suplemento Domingo (Lima) 1.15 de agosto 1982: 16C-17C. Se ocupa de C. Calvo, M. Lauer, A. Cisneros y otros poetas de esta generación y señala que el asesinato de $\mathrm{JH}$ y el suicidio de Luis Hernández son: "[...] dos muertes que signan distintivamente a esta promoción de poetas".

Oviedo, José Miguel. "Heraud en su entera imagen". El Comercio, Suplemento Dominical (Lima) 21 de junio 1964: 8. Reseña de Poesias completas y homenaje (1964). Analiza varios de los poemas. También en: Letras (Lima) 72-73 (1964): 323-325.

"Heraud: renuncia a los sueños". El Comercio, Suplemento Dominical (Lima) 13 de agosto 1961: 5. "Javier Heraud —ya que duda cabe- es la mejor esperanza que la poesía peruana tiene de las novísimas generaciones". También en: Poesias completas y homenaje. Lima: La Rama Florida, 1964. 238-240.

"Un río de 18 años". La Prensa, Suplemento 7 días del Perú y del mundo (Lima) 4 de setiembre 1960: 18. Reseña de El río, obra que encuentra espléndida sobretodo si se tiene encuenta la edad del autor. También en: Poesias completas y homenaje. Lima: La Rama Florida, 1964. 233-235.

"Vida y muerte en la poesía de Javier Heraud". Revista peruana de cultura (Lima) 3 (1964): 94-112. Analiza la obra de JH concentrándose en "El río" y "El viaje". También en: Poesias completas. 2a. ed. corr. y aum. Lima: Campodónico, 1973. 293319 y en Poesías completas. 3a. ed. Lima: Campodónico, 1975. 293-319.

Pavletich, Esteban. "Boceto de Javier Heraud" en Palabra de guerrillero: pequeña antología y homenaje. [Lima]: EWAGSA, [1970]. 3-5. "Como Melgar - también como Vallejo y como Adalberto Varallanos- presiente su temprana muerte y la anuncia reiteradamente".

Peralta, Alejandro. "Javier Heraud" en Palabra de guerrillero: pequeña antología y homenaje. [Lima]: EWAGSA, [1970]. 84-85. Poema dedicado a JH.

Pérez, Hildebrando. "Ausencias: (fragmento)". Piélago(Lima) 1.3 (diciembre 1963): 17. Poema dedicado a JH. También en: Javier Heraud y las voces panegíricas. Huari, Ancash, Perú: [Imp. Huari], 1964. 37.

"Bibliografia" en Poesias completas. 2a. ed. corr. y aum. Lima: Campodónico, 1973. 369-382. Bibliografía de y sobre JH. También en: Poesias completas. 3a. ed. 
Lima: Campodónico, 1975. 369-382; en: Poesías completas y cartas. Lima: Peisa, 1976. 237-248; y en Poesías completas. 4a. ed. Lima: Campodónico, 1986. 245258.

"Javier Heraud y Edgardo Tello: dos poetas, y un destino". Visión del Perú. 5 (junio 1970): 13-18. Evoca a estos dos poetas desaparecidos. De Heraud incluye: "Explicación" (poema) y "Explicación" (facsímil del testamento político de JH) y de Edgardo Tello: "Madre" y "A causa del dolor".

Pérez Fuentes, Gerardo. "Muerte y resurrección de Javier Heraud" en Javier Heraudy las voces panegíricas. Huari, Ancash, Perú: [Imp. Huari], 1964. 41. Poema dedicado a JH.

Portal, Magda. "Imprecación”. Piélago (Lima) 1.3 (diciembre 1963): 30-32. Poema dedicado a JH. También en: Palabra de guerrillero: pequeña antología y homenaje. [Lima]: EWAGSA, [1970]. 86-89 y en: Javier Heraudy las voces panegíricas. Huari, Ancash, Perú: [Imp. Huari], 1964. 27-29.

Portocarrero, Aníbal. "Elegía a la muerte de un poeta" en Javier Heraud y las voces panegíricas. Huari, Ancash, Perú: [Imp. Huari], 1964. 33. Poema dedicado a JH.

Portugal, Ana María. "Releyendo a Heraud". Correo (Lima) 19 de enero 1969: 10. "Heraud va contando lo que ve con sencillez, absorto en sus visiones, maravillado de la vida y de los seres".

"Testimonio". Homo (Arequipa, Perú) 1.3 (1966): 6. Elegía.

"Puerto Maldonado, los responsables de la violencia". Unidad (Lima) 59 (4 de junio 1963):

3. "Javier Heraud es la expresión del estado de ánimo de nuestra juventud; simboliza sus ideales, sus inquietudes, sus anhelos y su coraje".

Ribeyro, Julio Ramón. "El poeta asesinado". FEP(Lima)2 (octubre 1963): 3. "La muerte de Javier Heraud es simplemente más significativa porque es la primera vez, en el Perú, desde la época de Mariano Melgar, que un artista, un poeta, no se limita a protestar de viva voz, en poemas o firmando manifiestos, contra la injusticia social, sino que paga con su vida su amor a sus ideales". También en: Piélago(Lima) 1.3 (diciembre 1963): 8 y en: Poesias completas y homenaje. Lima: La Rama Florida, 1964. 214-215.

Romero, Elvio. "Mensaje y holocausto". FEP (Lima) 2 (octubre 1963): 3. Escrito en homenaje al poeta. También bajo "Palabras de Elvio Romero" en: Piélago (Lima) 1.3 (diciembre 1963): 10 y en Poesias completas y homenaje. Lima: La Rama Florida, 1964. 208-209.

Romualdo, Alejandro. "Héroe Heraud". Expreso (Estampa) (Lima) 18 de mayo 1975: 10. Homenaje de aniversario. También en: Piélago (Lima) 1.3 (diciembre 1963): 22; en Javier Heraudy las voces panegíricas. Huari, Ancash, Perú: [Imp. Huari], 1964. 5253; en: Poesias completas y homenaje. Lima: La Rama Florida, 1964. 211-212; y en: Unidad (Lima) 59 (4 de junio 1963): 8.

"Los poetas y los cerdos". Vistazo 6 (mayo 1971): 32-33. Recuerda a su amigo en el octavo aniversario de su muerte.

Rosario Vidal, Roberto. "A Heraud" en Palabra de guerrillero: pequeña antología y homenaje. [Lima]: EWAGSA, [1970]. 90-91. Poema dedicado a JH.

Rose, Juan Gonzalo. "La belleza de lo consciente". Expreso (Estampa) (Lima) 18 de mayo 1975: 11. "Todo en él fue sorprendente seriedad. Era serio al escribir, serio al sentarse en una mesa, serio cuando tomó el fusil de la guerrilla". 
Rowe, William. "Poesía peruana: los últimos diez años". Variedades tercer domingo de agosto (1974): 18-19. Se ocupa de los poetas de la Generación del 60. Sobre JH señala: "Una de las experiencias claves para los jóvenes poetas de los 60 fue la muerte del poeta Javier Heraud [...] la muerte de un poeta joven en tales circunstancias planteó de manera dramática el asunto de la acción vs. la poesía".

Ryan, Bryan, ed. "Heraud, Javier" en Hispanic Writers: a Selection of Sketches from Contemporary Authors. Detroit: Gale Research, 1991. Bio-bibliografia. "A promising young poet [...] a voice silenced before it had a chance to fully mature".

Salazar Bondy, Sebastián. "Dos libros, dos poetas". El Comercio, Suplemento Dominical (Lima) 28 de agosto 1960: 9. Se ocupa de Simple canción (1960) de Juan Gonzalo Rose y El río (1960) de JH. "Heraud se ha incorporado definitivamente a la poesía peruana como vanguardia de una 'nouvelle vague' que resume en sí, en su sabiduría e inspiración, la lenta elaboración de una lengua nueva que se inició con Eguren y Vallejo". También en: Poesías completas y homenaje. Lima: La Rama Florida, 1964. 231-232.

"Primera y última noticia de Javier Heraud" en Poesías completas. Lima: La Rama Florida, 1964. 7-10. Sirve de introducción a esta edición. Hace un recuento de los sucesos que llevaron al poeta a Puerto Maldonado y consecuentemente a su muerte. También en: Poesías completas. 2a. ed. corr. y aum. Lima: Campodónico, 1973. 913; en: Poesías completas. 3a. ed. Lima: Campodónico, 1975. 9-13; y en: Poesías completas. 4a. ed. Lima: Campodónico, 1986. 9-13.

Salinas, Serapio. "Yo era un río" y "A Javier Heraud". Homo (Arequipa, Perú) 1.3 1966):

7. Dos poemas dedicados a JH.

Sandoval C., Jorge. "Hablan los Heraud". Vistazo 2.24 (1973): 16-17. Jorge y Gustavo Heraud, padre y hermano de $\mathrm{JH}$, evocan los deseos, planes y proyectos del poeta. "Cuando Javier se fue a Cuba no tenía otra ilusión que hacer cine. Lo dice en sus cartas. Siempre me decía: en el Perú hay mucha historia, mucha leyenda para hacer películas muy bonitas".

Sanguinetti, Felipe. "Balada del niño guerrillero". Piélago (Lima) 1.3 (diciembre 1963): 27-29. Poema dedicado a JH. También en: Javier Heraud y las voces panegíricas. Huari, Ancash, Perú: [Imp. Huari], 1964. 24-26.

Sarmiento Olaechea, Edwin. "Casual encuentro con Javier Heraud". Correo (Lima) 5 de julio 1969: 8. Narra una conversación con JH.

Sefamí, Jacobo, comp. "Javier Heraud". Contemporary Spanish American Poets: a Bibliography of Primary and Secondary Sources. New York: Greenwood Press, 1992. 94-95. Bibliografía.

Sologuren, Javier. "A Javier Heraud" en Palabra de guerrillero: pequeña antología y homenaje. [Lima]: EWAGSA, [1970]. 92-93. Poema dedicado a JH. También en: Poesías completas y homenaje. Lima: La Rama Florida, 1964. 221-222.

"Recuerdo de Javier Heraud" en Gravitaciones \& tangencias. Miraflores, Lima: Colmillo Blanco, 1988. 304-308. "Ahora que releo sus poemas, se me hace patente, una vez más y con mayor nitidez, hasta qué punto el cuerpo total de su poesía nació de la entraña misma de una metáfora matriz, se nutrió de ella, creció con ella". También sirve de prólogo a Poesía completa. Lima: Peisa, 1989. 
Sullivan, Mary-Lee Lewis. "Presencia de la naturaleza en la obra de cinco poetas comprometidos de América Latina". Tesis de doctorado. Boston University, 1990. 130 p. Analiza el tema de la naturaleza en las obras de: Gioconda Belli, Rosario Murillo, Ernesto Cardenal, Otto René Castillo y Javier Heraud. En el capítulo sobre JH explora la interdependencia hombre-naturaleza que encuentra a menudo en su obra.

Valcárcel, Gustavo. "Javier Heraud" en Palabra de guerrillero: pequeña antología y homenaje. [Lima]: EWAGSA, [1970]. 94-96. Poema dedicado a JH.

"Javier Heraud vuelve a nacer" en Javier Heraud y las voces panegíricas. Huari, Ancash, Perú: [Imp. Huari], 1964. 23. Poema dedicado a JH. También en: Unidad (Lima) 59 (4 de junio 1963): 8.

Valdivia, Oscar. "Recuerdo y exaltación de Javier Heraud". Homo (Arequipa, Perú) 1.3 (1966): 8. Poema dedicado a JH.

Vargas Llosa, Mario. "Homenaje al poeta". Piélago (Lima) 1.3 (diciembre 1963): 11. "Yo no puedo hablar de él ahora como quisiera, la perplejidad y la ira me turban demasiado para evocar su obra y decir hasta qué punto son limpias y conmovedoras las imágenes de sus poemas, qué irreprochable su música". También bajo "Homenaje a Javier Heraud" en Poesias completas y homenaje. Lima: La Rama Florida, 1964. 200-202. "Vargas Llosa-Heraud: diálogo inédito". Punto (Lima) 1.1 (mayo 1981): 45. Incluye parte de la entrevista que en setiembre de 1961, sostuviera Mario Vargas Llosa con Javier Heraud acerca de la poesía en el Perú.

Vargas Romero, Oscar. "Hace 12 años murió el poeta, el guerrillero Javier Heraud". Correo (Lima) 15 de mayo 1975: 8. "Heraud era una esperanza para las letras nacionales, un joven valor $[\ldots]$ ".

Zegarra Diez Canseco, Gloria. "Javier Heraud: 1942-1963”. Alpha 6 (abril-junio 1966): 32-39. Nota biográfica. Incluye un poema inédito de JH dedicado a su hermano Gustavo. 
